Please do not remove this page

RMIT

UNIVERSITY

\title{
The influence of finite and infinite wall cavities on the sound insulation of double-leaf walls
}

Cambridge, Jason; Davy, John; Pearse, John

https://researchrepository.rmit.edu.au/esploro/outputs/9921860206701341/filesAndLinks?institution=61RMIT_INST\&index=null

Cambridge, J., Davy, J., \& Pearse, J. (2017). The influence of finite and infinite wall cavities on the sound insulation of double-leaf walls. Journal of the Acoustical Society of America, 141(1), 207-218.

https://doi.org/10.1121/1.4973570

Document Version: Accepted Manuscript

Published Version: https://doi.org/10.1121/1.4973570

Repository homepage: https://researchrepository.rmit.edu.au

(C) 2017 Acoustical Society of America

Downloaded On 2023/04/26 23:34:59 +1000

Please do not remove this page 
Thank you for downloading this document from the RMIT Research Repository.

The RMIT Research Repository is an open access database showcasing the research outputs of RMIT University researchers.

RMIT Research Repository: http://researchbank.rmit.edu.aul

\section{Citation:}

Cambridge, J, Davy, J and Pearse, J 2017, 'The influence of finite and infinite wall cavities on the sound insulation of double-leaf walls', Journal of the Acoustical Society of America, vol. 141, no. 1, pp. 207-218.

See this record in the RMIT Research Repository at:

https://researchbank.rmit.edu.au/view/rmit:39597

Version: Accepted Manuscript

Copyright Statement:

(c) 2017 Acoustical Society of America

Link to Published Version:

https://dx.doi.org/10.1121/1.4973570 
2 The influence of finite and infinite wall cavities on the sound insulation of double-leaf walls

3

4

5

6 7

8

9

10

14

15

16

17

18

19

20

21
Jason E. Cambridge ${ }^{1}$

University of Canterbury, Mechanical Engineering, Private Bag 4800, Christchurch 8140,

New Zealand

John L. Davy ${ }^{2}$

School of Science, Royal Melbourne Institute of Technology (RMIT) University, GPO Box 2476 Melbourne, Victoria 3001, Australia

John Pearse

University of Canterbury, Mechanical Engineering, Private Bag 4800, Christchurch 8140,

New Zealand

Running title: Insulation of finite and infinite walls

\footnotetext{
${ }^{1}$ Author to whom correspondence should be addressed. Electronic mail: JasonCambridge@hotmail.com

${ }^{2}$ Current address: CSIRO Infrastructure Technologies, Private Bag 10 Clayton South, Victoria 3169, Australia.
} 
22 Theories used to predict the sound insulation of double-leaf cavity wall systems are usually

23 based on the assumption that the wall is of an infinite extent. To account for the effect of the

24 finite extent of the wall, a limiting the angle of incidence, a finite radiation efficiency model or

25 the spatial windowing method are used in order to obtain realistic predictions. However, the

26 effects of the finite extent of the cavity are often not included. This paper presents an extension

27 of a finite two-dimensional cavity theory to include limp panels on each side of the cavity. It is

28 shown that the oblique incidence mass-air-mass resonance can only occur for certain frequencies

29 and certain angles of incidence. This is the reason why the infinite extent theories under predict

30 the sound insulation. The results of the predicted sound insulation agree with measurements

31 when the wall cavity is empty. To obtain agreement when the cavity is full of a porous sound

32 absorbing material, a flow resistivity of about one fifth of the measured value has to be used. Use

33 of the actual flow resistivity gives sound insulation values that are $10 \mathrm{~dB}$ too high. 


\section{INTRODUCTION}

The prediction and understanding of the sound insulation of double-leaf cavity wall

37 systems has dramatically improved since the development of the early classical prediction

38 models by Beranek and Work (1949) and London (1950). However, despite these improvements,

39 a detailed survey by Hongisto (2006) of more than twenty well-known prediction models

40 concluded that there is a high degree of variability in the results produced from these models and

41 no single model was capable of predicting the sound insulation of the entire spread of

42 commercially available walls. Thus there is still a need to develop better sound insulation

43 prediction models for double-leaf cavity walls.

$44 \quad$ Many of the theories used to predict the sound insulation of a wall assume that the wall is

45 of infinite extent. A typical example is the transfer matrix method which is well described by

46 Allard and Atalla (2009). To account for the effects of the finite size of the wall on the radiation

47 efficiency, these theories sometimes use a finite size radiation efficiency [see Appendix 12.A of

48 (Allard and Atalla, 2009) and Section II.H of (Brunskog, 2012)]. A variant of this approach is the

49 spatial windowing technique [see (Villot et al., 2001), (Villot and Guigou-Carter, 2005) and

50 (Vigran, 2009)].

For single leaf walls, Sewell (1970) showed that below the critical frequency, the finite

52 size radiation efficiency can be included by using a limiting angle of integration which depends

53 on the size of the wall compared to the wave length of sound.

For empty double-leaf cavity wall systems limiting the angle of integration does not

55 produce reasonable results. Consequently, an artificially high rate of sound attenuation is often

56 applied. For instance, while utilizing the transfer matrix method, Vigran (2009) sets "the power 
57 attenuation coefficient equal to $0.2 \mathrm{~m}^{-1}$ independent of frequency" and uses a cavity depth which

58 is slightly greater than the actual cavity depth. Davy (2010) also utilized an artificially high value

59 of effective cavity sound absorption and introduced regression equations for the effective sound

60 absorption of an empty wall cavity as a function of cavity depth. London (1950) used a panel

61 resistance which varied with angle of incidence to overcome the problem of empty cavities.

The research described in this paper presents an analytic two-dimensional model for

63 predicting the sound insulation of double-leaf cavity walls below their critical frequency. The

64 model enables a better understanding of the role of the finite cavity on the sound insulation of

65 double-leaf cavity walls and provides an explanation for the reason why an artificially high rate

66 of attenuation is needed within the theories which assume that the walls are of infinite extent.

Gösele and Gösele's (1977) model is extended by assuming that the two major air cavity

68 boundaries are limp panels with possibly different specified mass per unit area. This assumption

69 means that the solution is only valid to approximately half the critical frequencies of the panels.

70 The panels were assumed to be loaded on their sides opposite the air cavity with the infinite or

71 finite size panel radiation resistance when the panel was radiating into an infinite half space. The

72 radiation reactance was ignored.

Because the existing theories of panel radiation resistance do not cover panel waves

74 which are being attenuated with distance, the panel radiation resistance was calculated from first

75 principles using a two-dimensional model. The results obtained are in good agreement with three

76 dimensional models except at very low frequencies where the two-dimensional radiation

77 efficiencies are higher than the three dimensional radiation efficiencies Ljunggren (1991), Davy

78 (2009a). 
Prasetiyo (Prasetiyo, 2012; Prasetiyo and Thompson, 2012) has used the coupled

80 Waveguide Finite Element-Wave domain Boundary Element method to obtain results similar to

81 this paper for the angular dependence of the sound insulation of double-leaf cavity walls of finite

82 extent without sound insulation in their air cavities. One difference from this paper is that

83 Prasetiyo does not find the normal incidence mass-air-mass resonant frequency. This result of

84 Prasetiyo appears to be at odds with the experimental measurements of Brutel-Vuilmet et al.

85 (2006). Prasetiyo, Brutel-Vuilmet et al. (2005) and this paper all reach the conclusion that the

86 resonance frequencies of cavity walls of finite extent do not vary with the angle of incidence.

87 This observation explains why London's (1950) model underestimates the sound insulation of

88 cavity walls unless an artificial angular dependent panel resistance is introduced. It also explains

89 why the other infinite extent models have to introduce artificially high values for cavity

90 absorption, damping or attenuation.

\section{II. GOVERNING EQUATIONS}

In this paper, the time dependency is assumed to $e^{j \omega t}$ and is omitted from the equations.

93 Consider the sketch of a double-leaf wall system shown in Figure 1. Assuming that each wall

94 panel acts as a limp mass; the specific acoustic impedance $\left(Z_{i}\right)$ of each wall panel can be found

95 by taking into account the fluid loading effect of the surrounding air on each panel by 96 considering its radiation efficiency $\left(\sigma_{i}\right)$ and the characteristic impedance $\left(\rho_{0} c\right)$ of the air such 97 that

$$
Z_{i}=j \omega m_{i}+\sigma_{i} \rho_{0} c
$$

where the mass per unit area of each panel is $m_{i}$. 


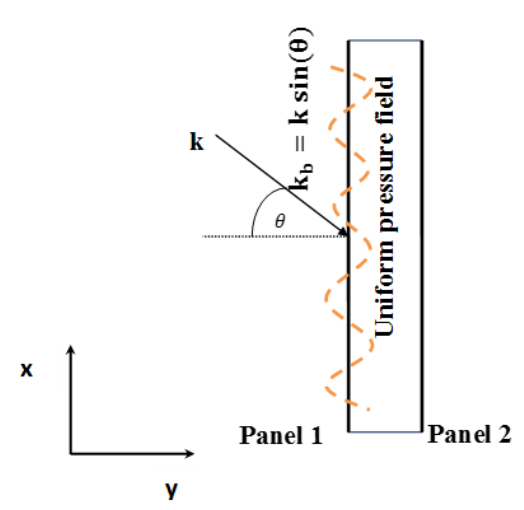

Figure 1 Co-ordinate system, incident and bending wave number used within the proposed pressure acting on it to its particle velocity $\left(v_{i}\right)$. Assuming that a plane harmonic wave is incident on panel one, Gösele and Gösele (1977) showed that once the depth of the wall cavity is small compared to the wavelength of the incident sound waves, a description of the air waves excited

107 in the cavity parallel to the $\mathrm{x}$-direction is sufficient for the required analysis. Consequently, the 108 incident sound pressure $\left(p_{i}\right)$ can be modelled as,

$$
p_{i}(x)=\hat{p}_{i} e^{j k_{b} x}
$$

109 where $k_{b}$ is the wave number of the bending wave on the panel such that $k_{b}=k \sin (\theta)$ as shown 110 in Figure 1. Hence the specific acoustic impedance of panels one and two can be found from 111 Equations (3) and (4) respectively

$$
\begin{gathered}
Z_{1}=\frac{2 p_{i}-p}{v_{1}}, \\
Z_{2}=\frac{p}{v_{2}}
\end{gathered}
$$

112 where the cavity pressure $(p)$ is created due to the motion of both wall panels. For frequencies 113 below the first resonance frequency perpendicular to the wall panel, Fahy (1985) showed that it 
114 can be assumed that the sound pressure across the depth within the wall cavity is uniform once

115 the depth of the cavity is small compared to the wavelength of the incident waves.

116 The rate of volume addition per unit volume $(q(x))$ due to the movement of the panels in the y-

117 direction can be found by considering Equations (3) and (4), such that:

$$
q(x)=\frac{v_{1}-v_{2}}{d}=\frac{1}{d}\left(\frac{2 p_{i}-p(x)}{Z_{1}}-\frac{p(x)}{Z_{2}}\right)
$$

118 where $d$ is the depth of the wall cavity. The situation considered in this paper is governed by the

119 following extension of Gösele and Gösele’s (1977) Equation (11),

$$
\frac{j \omega \rho_{0}}{\Xi+j \omega \rho_{0}} \frac{d^{2} p(x)}{d x^{2}}+k^{2} p(x)=-j \omega \rho_{0} q(x)
$$

120 where $(\Xi)$ is flow resistivity of the porous sound absorbing material in the wall cavity and the 121 last term in Gösele and Gösele's (1977) Equation (11) is replaced by the $q(x)$ of this paper. The 122 error in the sign of this last term in Gösele and Gösele's (1977) Equation (11) has been corrected.

123 The above equation extends Gösele and Gösele's (1977) theory by including the limp wall 124 panel's mass impedance and radiation efficiency as well as the effect of pressure doubling and 125 fluid loading. The solution for the wave equation given in Equation (6) showing the effect of the 126 reflected waves within the cavity is given in the next section.

\section{A. Solution to governing equations}

Substituting Equation (5) into Equation (6) and gives

$$
\frac{d}{\Xi+j \omega \rho_{0}} \frac{d^{2} p}{d x^{2}}+\left(\frac{d k^{2}}{j \omega \rho_{0}}-\frac{Z_{2}+Z_{1}}{Z_{1} Z_{2}}\right) p(x)=-\frac{2 p_{i}}{Z_{1}},
$$

130 with the general solution being in the form

$$
p(x)=p_{\text {forced }}(x)+p_{\text {reflected }}(x) .
$$

131 The reflected wave solution for the system is given by

$$
p_{\text {reflected }}(x)=\eta_{1} e^{\gamma x}+\eta_{2} e^{-\gamma x},
$$

132 where 


$$
\begin{gathered}
\gamma=\alpha+j \beta \\
\alpha=\frac{1}{\sqrt{2}} \sqrt{\sqrt{a^{\prime 2}+b^{\prime 2}}+a^{\prime 2}}
\end{gathered}
$$

133 And

$$
\beta=\frac{1}{\sqrt{2}} \sqrt{\sqrt{a^{\prime 2}+b^{\prime 2}}-a^{\prime 2}}
$$

134 with

$$
a^{\prime}=\frac{Z_{2}+Z_{1}}{Z_{2} Z_{1}} \frac{\Xi}{d}-k^{2}
$$

135 and

$$
b^{\prime}=\frac{\Xi k^{2}}{\omega \rho_{0}}+\frac{Z_{2}+Z_{1}}{Z_{2} Z_{1}} \frac{\omega \rho_{0}}{d} .
$$
waves in the cavity. The real part of $\gamma$ gives the rate of attenuation and the imaginary part gives the wave number. The value of $\gamma$ affects the radiation efficiency of the reflected waves and

139 consequently the sound power radiated.

140 For the forced solution, the sound wave incident on panel 1 at an angle $\theta$ to the normal can be

141 written as $\hat{p}_{i} e^{j k_{b} x}$, where

$$
k_{b}=k_{x}=k \sin \theta
$$

142 Equation (7) becomes

$$
\frac{d}{\Xi+j \omega \rho_{0}} \frac{d^{2} p(x)}{d x^{2}}+\left(\frac{d k^{2}}{j \omega \rho_{0}}-\frac{Z_{2}+Z_{1}}{Z_{1} Z_{2}}\right) p(x)=-\frac{2 p_{i} e^{j k_{b} x}}{Z_{1}}
$$

143 Assuming that $p_{f}=N e^{j k_{b} x}$ is the forced solution for the cavity pressure, the forced wave 144 amplitude $(N)$ can be found by substituting this particular solution into Equation (15) to give 


$$
N=\frac{j \omega \rho_{0} 2 p_{i}}{Z_{1} d}\left(\frac{1}{\left[k_{b}^{2} \frac{j \omega \rho_{0}}{\Xi+j \omega \rho_{0}}-k^{2}+\frac{j \omega \rho_{0}}{d} \frac{Z_{2}+Z_{1}}{Z_{1} Z_{2}}\right]}\right)
$$

145 As a result the full solution to the wave equation given by Equation (6) can be written in the

146 following form

$$
p(x)=N e^{j k_{b} x}+\eta_{1} e^{\gamma x}+\eta_{2} e^{-\gamma x} .
$$

147 The coefficients $\eta_{1}$ and $\eta_{2}$ can be found by assuming rigid boundary conditions such that $148 v(0)=v(l)=0$; this implies that $d p(x) / d x=0$ at $x=0$ and $x=l$.

149 Therefore;

$$
\begin{aligned}
& \eta_{1}=\frac{j k_{b} N\left(e^{-\gamma l}-e^{j k_{b} l}\right)}{\gamma\left(e^{\gamma l}-e^{-\gamma l}\right)}, \\
& \eta_{2}=\frac{j k_{b} N\left(e^{\gamma l}-e^{j k_{b} l}\right)}{\gamma\left(e^{\gamma l}-e^{-\gamma l}\right)} .
\end{aligned}
$$

150 Although Gösele and Gösele (1977) indicated that the solution for the sound pressure within the 151 wall cavity is in the form shown in Equation (17), they did not give the solution for $\eta_{1}$ and $\eta_{2}$ as 152 given by Equations (18) and (19) respectively. Instead Gösele and Gösele combined the effect of 153 the reflected waves into one equation. Consequently, the solutions presented here for $\eta_{1}$ and $\eta_{2}$ 154 provide an alternative approach to Gösele and Gösele's which will be vital in the study of the 155 effect of the mass-air-mass resonance frequency on the Sound Transmission Loss (STL) of 156 double-leaf wall systems. This effect is crucial in understanding why London's infinite model 157 under-predicts the STL as explained in Section V.

\section{III. FORCED RADIATION EFFICIENCY OF FINITE PANELS}

The wall panels are modelled as a vibrating strip placed within an infinite baffle as shown

160 in Figure 2. The radiated sound power over angles of radiation $(\varphi)$ between $\pi / 2$ and $-\pi / 2$ is 161 required in order to determine the forced radiation efficiency. The radiation efficiency $(\sigma)$ is, 


$$
\sigma=\frac{W_{\text {rad }}}{\rho_{0} c S\left|v_{n}\right|^{2}}
$$

162 where $W_{\text {rad }}$ is the radiated sound power, $S$ is the area of unit length of the strip and $v_{n}$ is the 163 normal root mean square (rms) velocity.

The radiated sound power can be determined from the radiated sound pressure for an 165 observer at a distance $(r)$ away from the vibrating strip. The distance $(r)$ is much greater than the distance $(x)$ between any two of the infinitesimal width mini-strips which make up the vibrating

167 strip shown in Figure 2; while the distance $(R)$ is the distance from the centre of the strip to an 168 observer in the far field.

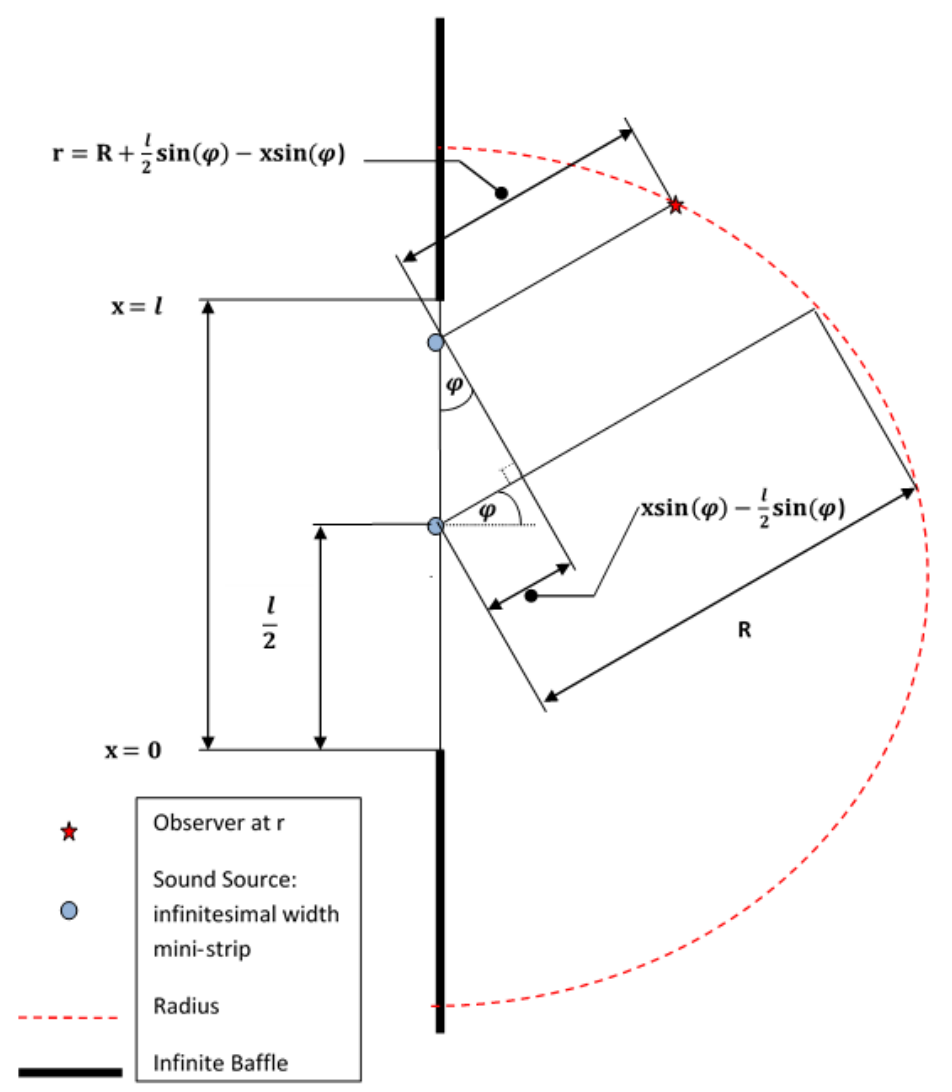


$173 k \delta x$ (i.e. the wave number of sound in air $k$ multiplied by the width of the infinitesimal width

174 mini-strip, $\delta x)$ the directivity of a vibrating mini-strip is almost omni-directional. As a result, the 175 radiated sound pressure is approximately equal to the radiated sound pressure of a zero order 176 cylindrical source of the same strength. Using the results of Jacobsen and Juhl, (2011) it can be 177 shown that the sound pressure at a distance $(r)$ away from the surface of the vibrating mini-strip 178 is

$$
p(r)=\frac{U_{0} \rho_{0} c \pi k \delta r}{2} \sqrt{\frac{2}{\pi k r}} e^{j\left(-k r+\frac{\pi}{4}\right)}
$$

179 The volume velocity per unit length $q_{0}$ of a cylinder of radius $\delta r$ is equal to $2 \pi \delta r U_{0}$. Since the 180 radiation into the half space is of interest, $q_{0}=\pi \delta r U_{0}$ in this case. Substituting the half space 181 volume velocity into Equation (21) gives

$$
p(r)=\frac{q_{0} \rho_{0} c k}{2} \sqrt{\frac{2}{\pi k r}} e^{j\left(-k r+\frac{\pi}{4}\right)} .
$$

182 Fahy (1985) stated that it can be assumed that the sound field produced by a small volume 183 velocity source is independent of the detailed form of distribution of velocity over the source 184 surface. For an element $\delta x$ of the infinitely long narrow strip the volume velocity, $q_{0}=v_{n} \delta x$. 185 Therefore, Equation (22) can be re-arranged to give

$$
p(x, r)=\rho_{0} c \sqrt{\frac{k}{2 \pi r}} e^{j\left(-k r+\frac{\pi}{4}\right)} v_{n} \delta x
$$

186 From Figure 2, if the observer is at a distance $r=R-\frac{l}{2} \sin (\varphi)+x \sin (\varphi)$, Equation (23) can be 187 written as 


$$
p(x, \varphi)=\rho_{0} c \sqrt{\frac{k}{2 \pi\left(R+\frac{l}{2} \sin (\varphi)-x \sin (\varphi)\right)}} e^{j\left(-k\left(R+\frac{l}{2} \sin (\varphi)-x \sin (\varphi)\right)+\frac{\pi}{4}\right)} v_{n} \delta x .
$$

188 Assuming that the distance from the centre of the cylinder/strip $(R)$ is significantly greater than

$189 \frac{l}{2} \sin (\varphi)-x \sin (\varphi)$, it can be assumed that $\sqrt{R+\frac{l}{2} \sin (\varphi)-x \sin (\varphi)}=\sqrt{R}$. Consequently,

190 Equation (24) can be written as

$$
p(x, \varphi)=\rho_{0} c \sqrt{\frac{k}{2 \pi R}} e^{j\left(-k\left(R+\frac{l}{2} \sin (\varphi)-x \sin (\varphi)\right)+\frac{\pi}{4}\right)} v_{n} \delta x
$$

191 The sound pressure radiated from the finite width strip can be found by integrating over the

192 width of the finite width strip such that

$$
p(x, \varphi)=\rho_{0} c \sqrt{\frac{k}{2 \pi R}} \int_{0}^{l} e^{j\left(-k\left(R+\frac{l}{2} \sin (\varphi)-x \sin (\varphi)\right)+\frac{\pi}{4}\right)} v_{n} d x
$$

193 For the forced wave

$$
v_{n}=v_{\text {forced }} e^{j k_{b} x}
$$

194 where $v_{\text {forced }}$ is the amplitude of the normal velocity of the forced wave and $k_{b}=k \sin (\theta)$ is 195 the wave number of the forced wave on the strip. Consequently, the radiated sound pressure due 196 to the forced bending wave can be found by substituting Equation (27) into Equation (26) such 197 that

$$
p_{\text {forced }}(x, \varphi, \theta)=\rho_{0} c \sqrt{\frac{k}{2 \pi R}} e^{j\left(-k\left(R+\frac{l}{2} \sin (\varphi)\right)+\frac{\pi}{4}\right)} v_{\text {forced }} \int_{0}^{l} e^{j x\left(k \sin (\varphi)+k_{b}\right)} d x
$$

198 Solving the integral in Equation (28) gives 


$$
p_{\text {forced }}(\varphi, \theta)=\rho_{0} c \sqrt{\frac{k}{2 \pi R}} e^{j\left(-k\left(R+\frac{l}{2} \sin (\varphi)\right)+\frac{\pi}{4}\right)} v_{\text {forced }}\left[\frac{\left(e^{j l\left(k \sin (\varphi)+k_{b}\right)}-1\right.}{j\left(k \sin (\varphi)+k_{b}\right)}\right] \text {. }
$$

199 Jacobsen and Juhl (2011) showed that in the far field both the sound pressure and particle 200 velocity are in phase. As a result, the radiated sound power per unit length over all angles of 201 radiation is

$$
W_{\text {rad }}=R \int_{-\frac{\pi}{2}}^{\frac{\pi}{2}} I d \varphi=R \int_{-\frac{\pi}{2}}^{\frac{\pi}{2}} \frac{|p|^{2}}{\rho c} d \varphi
$$

202 The pressure modulus squared of Equation (29) can be written as

$$
|p(\varphi, \theta)|^{2}=\rho_{0}^{2} c^{2} \frac{k}{\pi R} v_{\text {forced }}^{2} \frac{1-\cos \left(l\left(k \sin (\varphi)+k_{b}\right)\right)}{\left(k \sin (\varphi)+k_{b}\right)^{2}}
$$

203 Substituting Equation (31) into Equation (30) gives

$$
\sigma_{\text {forced }}(\varphi, \theta)=\frac{k l}{2 \pi} \int_{-\frac{\pi}{2}}^{\frac{\pi}{2}} \operatorname{sinc}^{2}\left(\frac{k l}{2}(\sin (\varphi)+\sin (\theta))\right) d \varphi .
$$

The forced radiation efficiency (in $\mathrm{dB}$ ) of the two-dimensional vibrating strip can be seen

205 in Figure 3. The results shown are similar to that obtained by both Davy (2009a) and Sato (1973)

206 with the corresponding finite radiation efficiency at grazing incidence (i.e. $90^{\circ}$ ) being observed. 


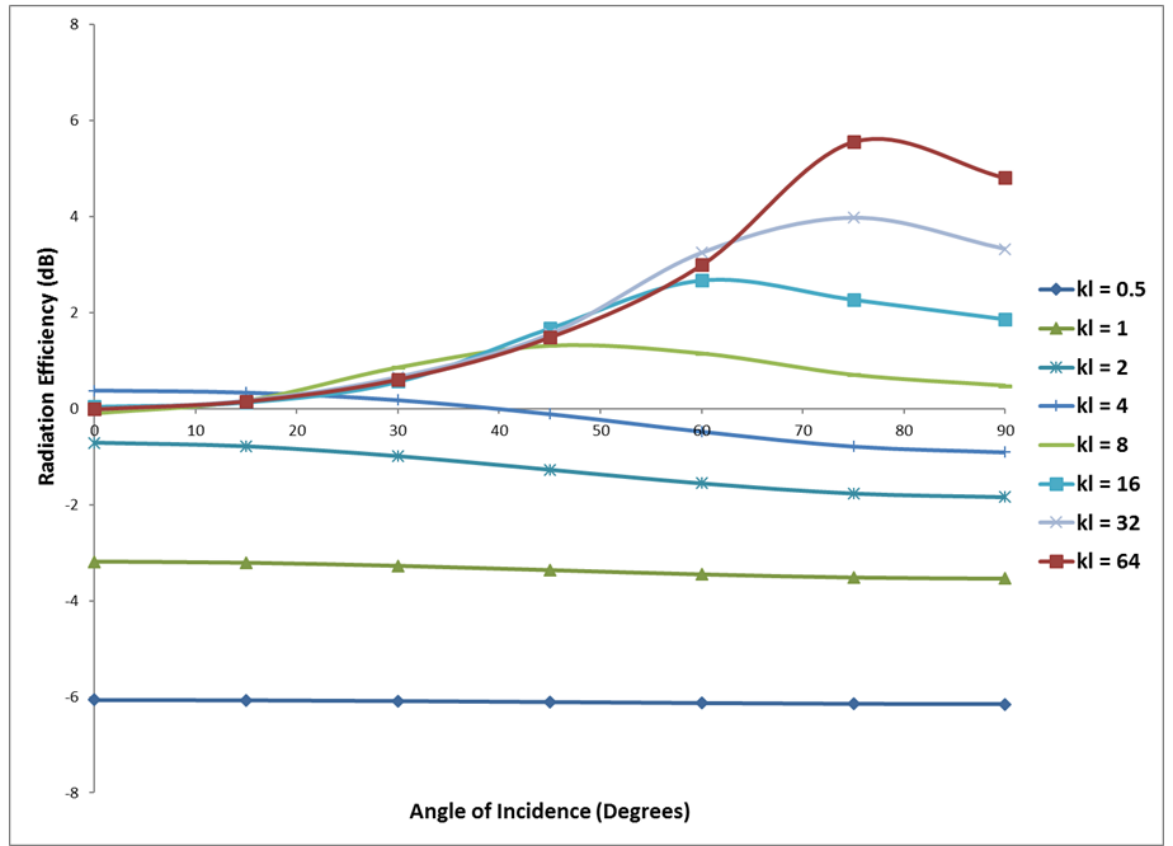

Figure 3 Forced radiation efficiency of a vibrating strip (color online)

A two-dimensional vibration strip model has been derived and developed for the radiation efficiency of forced waves. The approach presented here is different from that used by Davy (Davy, 2009a), Ljunngren (1991), Sato (1973) and Sewell (1970) in their models for the forced radiation efficiency. During the development of this model it was assumed that:

- The radiated sound pressure from an infinitesimal width vibrating strip is equal to the radiated sound pressure of a zero order cylindrical source with the same volume velocity per unit length

- The radiated sound pressure is independent of the detailed form of distribution of the volume velocity over the surface

- The radiated sound pressure and the particle velocity are in phase

The forced wave which is radiated into the wall cavity will produce reflected waves with different wavelengths and rates of attenuation. As a result, the radiation efficiency of the reflected waves will be different from that of the forced wave. Consequently, in Section IV an iterative numerical approximation is derived for the radiation efficiency of the reflected waves within the wall cavity. An iterative approach is needed because the radiation efficiency of the wave in the wall leaf forced by a reflected wave in the cavity is dependent on its rate of attenuation $(\operatorname{Re}(\gamma))$, which is dependent on the impedance of the wall panels, depth and airflow 
226 resistivity of the wall cavity (see Equation (9)). The wall panel impedance is dependent on the

227 fluid loading effect which is determined by the radiation efficiency of the reflected waves.

228 Therefore, in order to determine the radiation efficiency of these waves, initial approximations 229 must be made for both $\gamma$ and their radiation efficiencies.

\section{IV. RADIATION EFFICIENCY OF THE REFLECTED CAVITY WAVES}

The radiated sound pressure in the far field due to the reflected waves in the wall cavity

232 which excite the wall panels can be solved by substituting the normal velocity due to the

233 reflected waves into Equation (26). The normal velocity due to the reflected waves is

$$
v_{n, \pm}=v_{o \pm} e^{ \pm \gamma x}
$$

234 where the \pm corresponds to the signs used for $\gamma$ shown in Equation (17) and $v_{O \pm}$ is the amplitude 235 of the two reflected waves. Substituting Equation (33) into Equation (26) gives,

$$
p_{\gamma \pm}(x, \varphi, t)=\rho c \sqrt{\frac{k}{2 \pi R}} e^{j\left(\omega t-k\left(R+\frac{l}{2} \sin (\varphi)\right)+\frac{\pi}{4}\right)} v_{o \pm} \int_{0}^{l} e^{j x(k \sin (\varphi))} e^{ \pm \gamma x} d x
$$

236 Because the radiation efficiency depends on $\gamma$ and $\gamma$ depends on the radiation efficiency, the

237 correct values are obtained by iteration. As a first approximation, the amplitude and phase of the

238 reflected waves are assumed initially to be constant along the length of the cavity. This means

239 that $\gamma$ is assumed to be zero initially. Utilizing this assumption and following the same procedure

240 shown in the proceeding section it can be shown that the radiated power and radiation efficiency

241 of the reflected waves are given by,

$$
W_{\gamma=0}(\varphi)=\rho c \frac{k}{\pi l} v_{o \pm}^{2} \int_{-\frac{\pi}{2}}^{\frac{\pi}{2}} \frac{1-\cos (k l \sin (\varphi))}{\sin ^{2} \varphi} d \varphi
$$

242 and 


$$
\sigma_{\gamma=0}(\varphi)=\frac{k l}{2 \pi} \int_{-\frac{\pi}{2}}^{\frac{\pi}{2}} \operatorname{sinc}^{2}\left(\frac{k l}{2} \sin (\varphi)\right) d \varphi
$$

243 Equation (36) gives the first approximation for the radiation efficiency of the reflected waves 244 under the assumption that $\gamma=0$.

246 efficiency of the reflected waves into the forced wave impedance of the wall panel. The radiated 247 power and radiation efficiency can then be found from the following

$$
W_{\gamma \pm}(\varphi)=\rho c \frac{k}{\pi} v_{o \pm}^{2} \int_{-\frac{\pi}{2}}^{\frac{\pi}{2}}\left(\frac{2 \sin ^{2}\left(\frac{l}{2}(k \sin (\varphi) \mp j \gamma)\right)}{(k \sin (\varphi) \mp j \gamma)^{2}}\right) d \varphi
$$

248 and

$$
\sigma_{\gamma \pm}(\varphi)=\frac{k l}{2 \pi} \frac{v_{o \pm}^{2}}{\left|v_{n \pm}^{2}\right|} \int_{-\frac{\pi}{2}}^{\frac{\pi}{2}}\left(\operatorname{sinc}^{2}\left(\frac{l}{2}(k \sin (\varphi) \mp j \gamma)\right) d \varphi\right.
$$

249 Now since $v_{n \pm}=v_{o} e^{ \pm \gamma x}$ and $\gamma$ is a complex number, the magnitude of $v_{n \pm}$ can be found from 250 the following

$$
\left|v_{n \pm}\right|=v_{o \pm}\left|e^{ \pm \gamma x}\right|=v_{o \pm}\left|e^{ \pm \gamma_{\text {real }} x}\right|\left|e^{ \pm \mathrm{j} \gamma_{\text {imaginary }} x}\right|=v_{o \pm}\left|e^{ \pm \gamma_{\text {real }} x}\right|
$$

251 Therefore $\left|v_{n \pm}\right|^{2}$ integrated over the length of the strip can be found from

$$
\left|v_{n \pm}\right|^{2}=v_{o \pm}^{2} \int_{0}^{l}\left|e^{ \pm 2 \gamma_{\text {real }} x}\right|=v_{o \pm}^{2}\left(\frac{e^{ \pm 2 \gamma_{\text {real }} l}-1}{2 \gamma_{\text {real }}}\right)
$$

252 Substituting Equation (40) into Equation (38) gives the radiation efficiency due to the excitation

253 of the panel due to the reflected waves within the wall cavity as

$$
\sigma_{\gamma_{ \pm}}(\varphi)=\frac{k l}{2 \pi}\left(\frac{e^{ \pm 2 \gamma_{\text {real }} l}-1}{2 \gamma_{\text {real }}}\right) \int_{-\frac{\pi}{2}}^{\frac{\pi}{2}}\left(\operatorname{sinc}^{2}\left(\frac{l}{2}(k \sin (\varphi) \mp i \gamma)\right) d \varphi\right.
$$


254 An additional resistance term $r / \rho_{o} c$ was added to $\sigma_{\gamma}$. For the empty cavity case, the only 255 damping within the model is provided by the radiation efficiency. Thus it is necessary to include

256 some extra damping in the model to take account of the damping in the real system because the 257 limp panel assumption means that the panel also has no damping. This extra included damping is 258 mostly needed at the mass-air-mass resonant frequency.

\section{V. SOUND TRANSMISSION LOSS OF INFINITE DOUBLE-LEAF WALL SYSTEMS}

260 The STL is defined simply as the logarithm of the ratio of the incident sound power upon the 261 wall to the sound power transmitted through it. Written in terms of the interaction of the incident $262\left(p_{i}\right)$ and transmitted sound pressure $\left(p_{t}\right)$ the sound transmission coefficient $(\tau)$ for an infinite 263 panel can be found from

$$
\tau=\left|\frac{p_{t}}{p_{i}}\right|^{2}
$$

264 By assuming continuity of the particle velocity, London showed the relationship between the

265 transmitted pressure of an infinite wall system $\left(p_{\infty, t r a n s}\right)$ and particle velocity is

$$
p_{\infty, \text { trans }}=\left|\frac{\rho_{o} c v_{2}}{\cos (\theta)}\right|,
$$

266 where $v_{2}$ is the particle velocity on the panel 2. $v_{2}$ is dependent on the pressure within the wall

267 cavity and the specific acoustic impedance as shown in Equation (4). As a result

$$
p_{\infty, \text { trans }}=\frac{\rho_{o} c}{\cos (\theta)}\left|\frac{p_{\infty, \text { cavity }}}{Z_{2}}\right|
$$

268 where

$$
p_{\infty, \text { cavity }}=\left|N e^{j k_{b} x}\right|=|N| .
$$

269 and $N$ is the amplitude of the forced wave given by Equation (16).

270 Beranek (1971) showed that the forced radiation efficiency of an infinite plate $\left(\sigma_{\infty}\right)$ due to 271 airborne excitation is given by

$$
\sigma_{\infty}=\frac{1}{\sqrt{1-\sin ^{2}(\theta)}}=\frac{1}{\cos (\theta)} .
$$


272 Consequently Equation (43) can be written in terms of $\sigma_{\infty}$ as

$$
p_{\infty, \text { trans }}=\rho_{o} c \sigma_{\infty}\left|\frac{p_{\infty, \text { cavity }}}{Z_{2}}\right|
$$

273 From Equation (47) it can be seen that the transmitted pressure squared is dependent only on the 274 amplitude of the forced waves in the infinite model. This is due to the underlying assumption 275 within this model that the panels and by extension the wall cavity are infinitely long such that 276 waves excited within the system keep travelling without any reflections. Consequently from 277 Equation (17) the sound pressure within the cavity for the infinite model is only dependent on the 278 forced waves as shown in Equation (45).

279 The STL for the infinite model $\left(S T L_{\infty}\right)$ can be found by assuming that the incident 280 pressure in Equation (42) is equal to one. This assumption can be made as the transmitted 281 pressure is also dependent on the incident pressure; since the STL involves the ratio of these two 282 sound pressures any value can be assumed for the incident sound pressure. As a result, the sound 283 transmission loss for the infinite model can be found from

$$
S T L_{\infty}=10 \log _{10}\left(\frac{1}{p_{\infty, \text { trans }}^{2}}\right) .
$$

284 The STL prediction obtained from Equation (48) compared to London's model for an empty 285 double-leaf infinite wall system with equal mass of $12.3 \mathrm{~kg} / \mathrm{m}^{2}$ for both wall panels and a cavity 286 depth of $90 \mathrm{~mm}$ can be seen in Figure 4. 


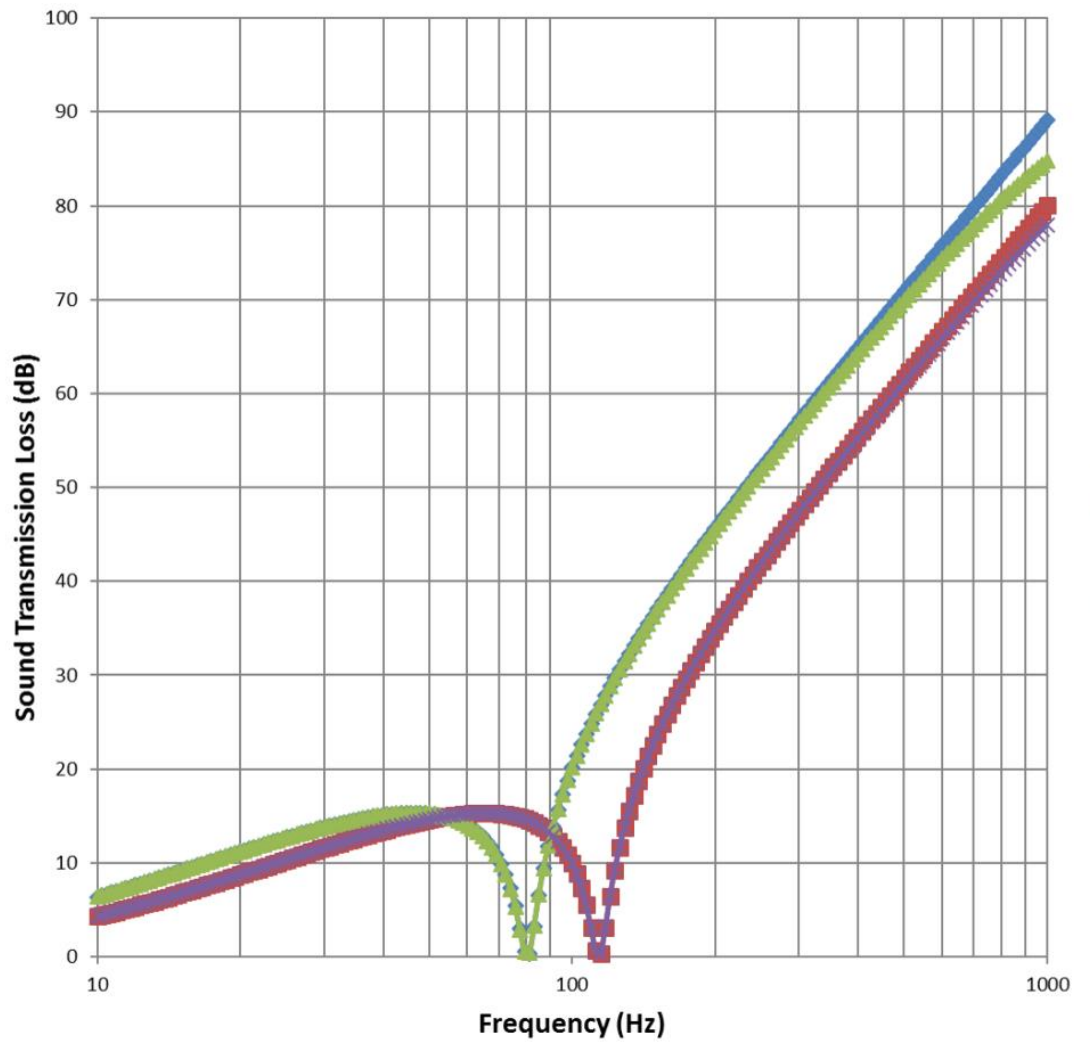

\section{$\leadsto$ Cambridge Infinite $0^{\circ}$ - -Cambridge Infinite $45^{\circ}$ \\ - London $0^{\circ}$ \\ $\because$ London $45^{\circ}$}

287

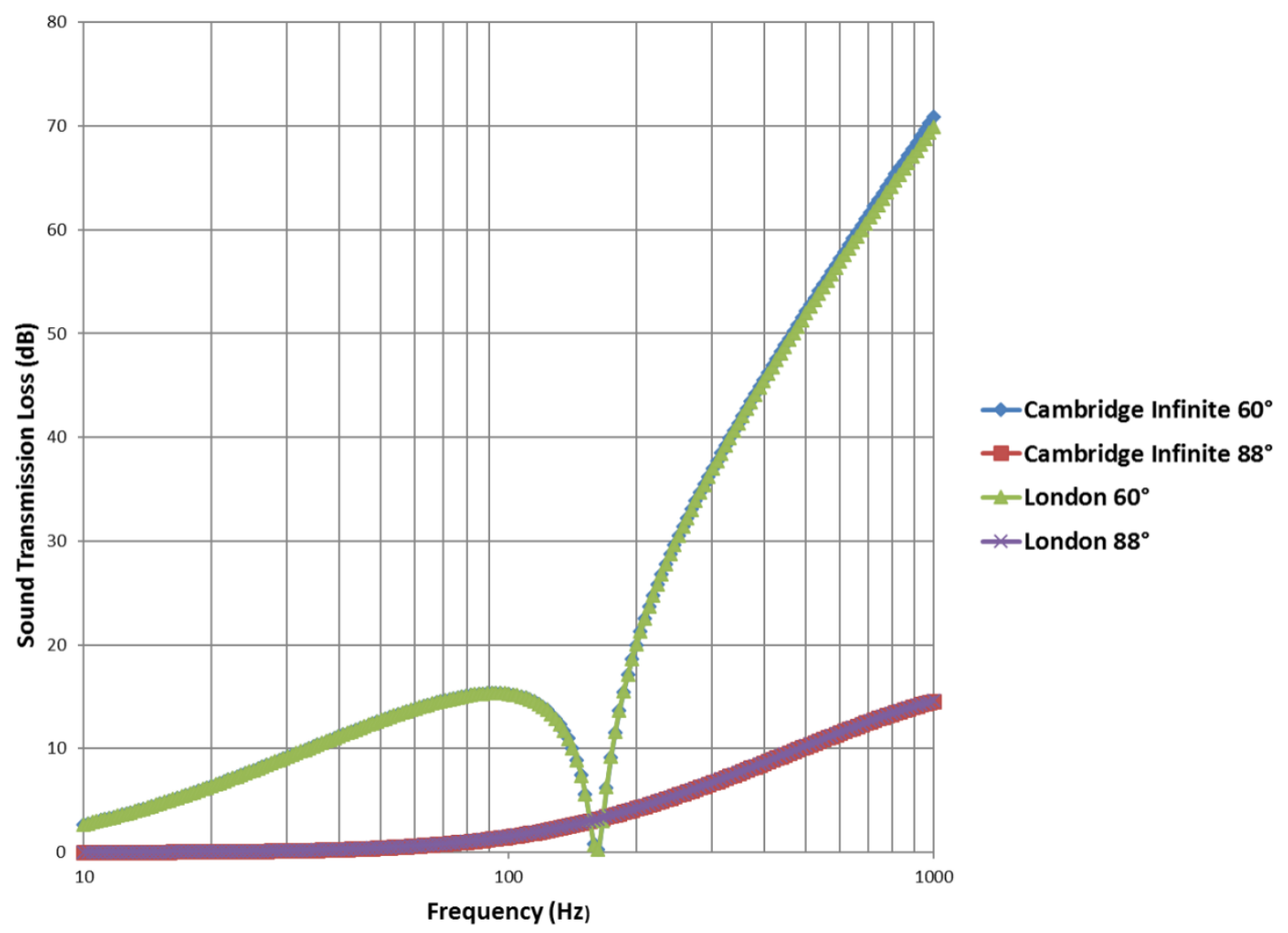



double-leaf wall at different angles of incidence (color online) compare well with the results obtained from London's work. The discrepancies between both models at the higher frequencies are due to the effects of the first cross cavity mode which is 295 taken into account in London's model but not in the presented model since a constant sound 296 pressure across the cavity is assumed. This figure also shows that the mass-air-mass resonance 297 frequency varies with angle of incidence, with the lowest of these occurring at the normal mass298 air-mass resonance frequency.

\section{VI. SOUND TRANSMISSION LOSS OF FINITE DOUBLE-LEAF WALL SYSTEMS}

In Section V it was shown that a model predicting similar results as London's for infinite

However, for the finite wall system both the forced and reflected waves in the cavity dictate the response of the entire system. In this section it is assumed that the radiation efficiency of the vibration created in the leaves of the wall by the reflected waves in the cavity are the same as the 305 radiation efficiency of the vibration created in the leaves of the wall by the forced waves in the cavity. This avoids the need for iteration in the calculations.

\section{A. Incident Sound Power}

One major problem associated with the infinite model, is that it predicts that no sound will be transmitted at grazing incidence due to the radiation efficiency of the infinite panels. As a result, some researchers utilize a finite radiation efficiency as a substitute for $1 / \cos (\theta)$ when modelling finite wall systems. For example, the wave impedance of an infinite wall panel is

312 equal to the ratio of the incident sound pressure and the normal particle velocity such that 


$$
Z_{i}=\frac{p_{i}}{u_{i} \cos (\theta)}=\frac{Z_{c}}{\cos (\theta)}=\frac{\rho c}{\cos (\theta)}
$$

313 where $Z_{c}$ is the characteristic impedance of air such that $Z_{c}=p_{i} / u_{i}$. Rindel (1975) showed that 314 the sound power incident on an infinite panel can be found from

$$
W_{i \infty}=\int_{S} \frac{1}{2} \operatorname{Re}\left(P_{i} u_{i y}^{*}\right) d S=\frac{p^{2}{ }_{i, r m s} S}{\operatorname{Re}\left(Z_{i}\right)}=\frac{p^{2}{ }_{i, r m s}}{\rho c} S \cos (\theta),
$$

315 where the subscript $y$ corresponds to the co-ordinate system shown in Figure 1, the amplitude 316 variables $P_{i} u_{i y}^{*}$ are peak amplitudes rather than rms amplitudes and the area $(S)$ of a unit length 317 of the strip is $l$. The incident sound power is

$$
W_{i \infty}=\frac{p^{2}{ }_{i, r m s}}{\rho c} l \cos (\theta) .
$$

318 In order to account for the finite size of the wall panel, the $\cos (\theta)$ term in Equation (51) can be 319 replaced by the inverse of the forced radiation efficiency to give

$$
W_{i}=\frac{p^{2}{ }_{i, r m s} l}{\rho c \sigma_{\text {forced }}} \text {. }
$$

320

321

322

323

324

325

326

327

328

329

Rindel (1975) utilized such a substitution and commented that this was similar to the way in which it was employed by Heckl (1964). Rindel stated that the use of the radiation efficiency in this manner also implies that the incident power per unit area is small when $k l$ is large and increases when $k l$ decreases. The deformation of the sound field by diffraction effects was given as the explanation for the reason why this occurs. The use of the finite radiation efficiency in this way is similar to spatial windowing technique developed by Villot et al. (2001). In this initial introduction of the theory, the spatial window was applied to both the sound pressure field and the vibration before calculating the radiated field. According to Vigran (2009) and Allard and Atalla (2009) this technique was modified by Villot and Guigou-Carter (2005) by only taking the spatial window into account on the transmitted side; an approach which Vigran (2009) employed 
330 when developing his one dimensional finite radiation impedance method. Ghinet and Atalla

331 (2001) also created an alternative method to the Villot et al. (2001) spatial windowing technique

332 by using a finite rather than an infinite forced radiation efficiency to correct the infinite sound

333 transmission coefficient to a finite one.

However, despite Rindel's (1975) and Villot et al's (2001) successful substitution of the

335 finite radiation efficiency in the manner described, this approximation cannot be done on both

336 the transmitted power and the incident power. This was the reason for Villot and Guigou-

337 Carter's (2005) correction. Furthermore, if this approximation is done for the incident power, it

338 should only be utilized when finding the angular dependent sound transmission loss and not

339 when finding the diffuse sound field sound transmission loss. This is because the $\cos (\theta)$ term

340 used when calculating the diffuse sound field transmission coefficient (as shown in Equation

341 (60)) represents the projected area of the sound field onto the wall panel. Consequently, a further

342 substitution of the finite radiation efficiency for this $\cos (\theta)$ term cannot be done. As a result,

343 Equation (51) should be used when predicting the diffuse field STL while Equation (52) should

344 be utilized when calculating the angular dependent STL. The use of the radiation efficiency in

345 this manner has been validated by Brunskog (2012) while evaluating Davy's (2009b) theory.

346

350 radiated sound pressure of the vibrating strip can be found by replacing the velocity in Equation

351 (28) with the total velocity due to both the forced and reflected waves such that 


$$
p(x, \varphi, \theta, t)=\rho c \sqrt{\frac{k}{2 \pi R}} \int_{0}^{l} e^{j\left(\omega t-k\left(R+\frac{l}{2} \sin (\varphi)-x \sin (\varphi)\right)+\frac{\pi}{4}\right)} v_{n, \text { total }}(x) d x,
$$

352 where,

$$
v_{n, \text { total }}(x, \theta)=v_{\text {forced }} e^{j k_{b} x}+v_{o+} e^{\gamma x}+v_{o-} e^{-\gamma x}
$$

353 Furthermore, it can be shown that the magnitude of the pressure squared is given by

$$
|p(\varphi, \theta)|^{2}=\rho^{2} c^{2} l\left(\frac{k}{2 \pi R}\right)\left|v_{\text {forced }} \operatorname{sinc}\left(\frac{A}{2}\right)+v_{o+} \operatorname{sinc}\left(\frac{B}{2}\right)+v_{o-} \operatorname{sinc}\left(\frac{C}{2}\right)\right|^{2}
$$

354 where,

$$
\begin{gathered}
A=k l \sin (\varphi)+k_{b}, \\
B=k l \sin (\varphi)-j \gamma l, \\
\text { and } \\
C=k l \sin (\varphi)+j \gamma l .
\end{gathered}
$$

355 Consequently,

$$
W_{\text {total }}(\varphi, \theta)=\rho c l\left(\frac{k}{2 \pi}\right) \int_{-\frac{\pi}{2}}^{\frac{\pi}{2}}\left|v_{\text {forced }} \operatorname{sinc}\left(\frac{A}{2}\right)+v_{o+} \operatorname{sinc}\left(\frac{B}{2}\right)+v_{o-} \operatorname{sinc}\left(\frac{C}{2}\right)\right|^{2} d \varphi
$$

356 The velocity amplitude in Equation (56) for the forced and reflected waves can be found from

$$
\begin{gathered}
v_{\text {forced }}=\frac{N}{Z_{2}}, \\
v_{o+}=\frac{\eta_{1}}{Z_{2}} \\
v_{o-}=\frac{\eta_{2}}{Z_{2}}
\end{gathered}
$$

357 where $N$ is the pressure amplitude due to the forced wave (Equation (16)), $\eta_{1}$ and $\eta_{2}$ are the 358 pressure amplitudes due to the reflected waves as given in Equations (18) and (19) respectively: 
$359 Z_{2}$ is the impedance of the Panel 2 with the appropriate radiation efficiency used for the fluid 360 loading effect.

\section{Physical Explanation For The Under-Prediction Of London's Model}

362 Based on the above discussion the angular dependent transmission coefficient can be found from

363 the ratio of the total transmitted power given by Equation (56) to the incident power given by 364 Equation (52). The resulting angular dependent STL results for a 3.05 by $2.44 \mathrm{~m}$ gypsum double 365 wall system with a $90 \mathrm{~mm}$ cavity can be seen in Figure 5. A cavity length of $2.44 \mathrm{~m}$ was utilized 366 when calculating the results shown.

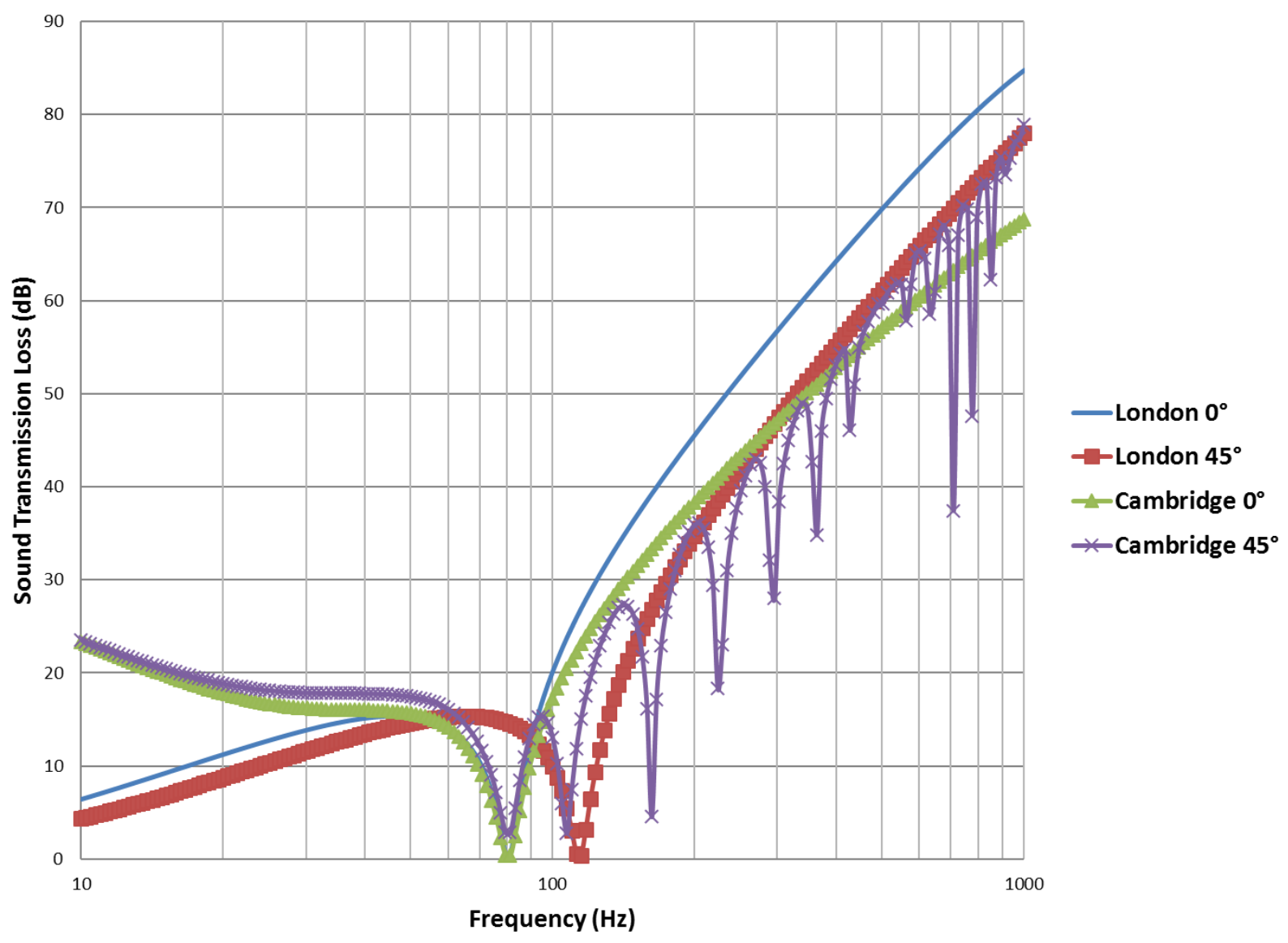




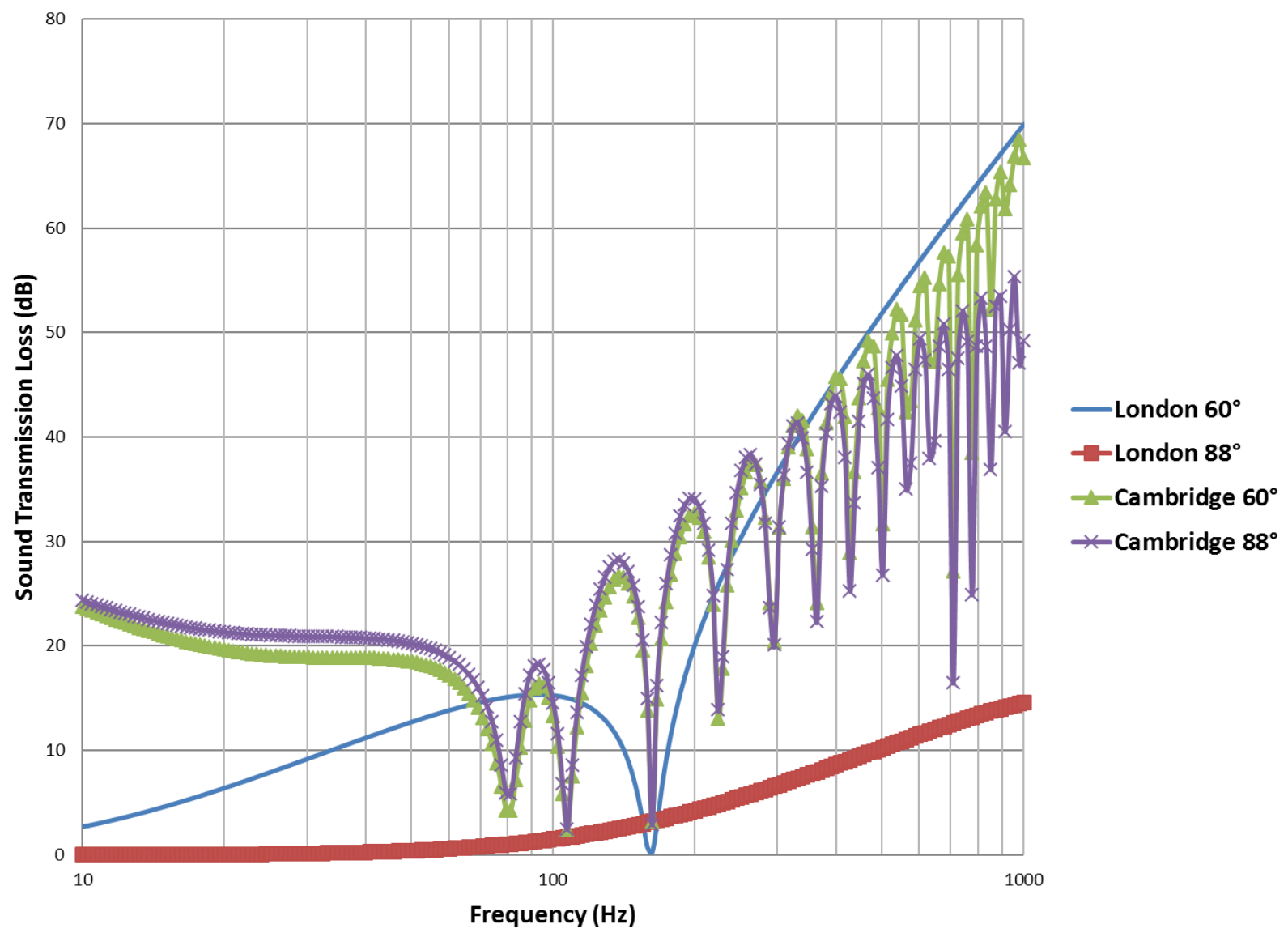
incidence the oblique mass-air-mass resonance frequency occurs at the normal mass-air-mass normal mass-air-mass resonance frequency being independent of the angle of incidence. The 378 dips in the STL above the normal mass-air-mass resonance frequency shown in Figure 5 are due

Figure 5 Comparison between London's infinite model and the proposed finite model assuming that the forced and reflected waves have the same radiation efficiency (color online)

The results in Figure 5 show that the oblique mass-air-mass resonance frequency for the finite model does not vary with the angle of incidence as in London's model. Instead, for all angles of frequency. The presence of the reflected waves within the wall cavity is responsible for the 
379 to the cavity resonances associated with the finite size of the wall cavity. The results shown 380 indicate that these resonance frequencies do not vary with the angle of incidence.

381 In order to determine how the prediction results compare to measurements reported by Warnock 382 (2010) the diffuse sound field sound transmission coefficient $\left(\tau_{d}\right)$ was calculated using Equation 383 (60) and averaged into $1 / 3$ octave bands.

$$
\tau_{d}=2 \int_{0}^{\pi / 2} \tau \sin (\theta) \cos (\theta) d \theta
$$

384 The results for a $16 \mathrm{~mm}$ gypsum (density $770 \mathrm{~kg} / \mathrm{m}^{3}$ ) double-leaf walls with a $90 \mathrm{~mm}$ cavity 385 without sound absorbing material in the wall cavity can be seen in Figure 6. The measured sound 386 insulation results TL-92-265 to TL-92-267 (from Warnock(2010)) in Figure 6 contain $40 \mathrm{~mm}$ 387 double steel studs spaced at $610 \mathrm{~mm}$ centers with a $10 \mathrm{~mm}$ gap between the separate studs, while 388 TL-92-262 to TL-92-264 contain $90 \mathrm{~mm}$ steel studs on $813 \mathrm{~mm}$ centers. These walls have critical 389 frequencies of $2.5 \mathrm{kHz}$. 


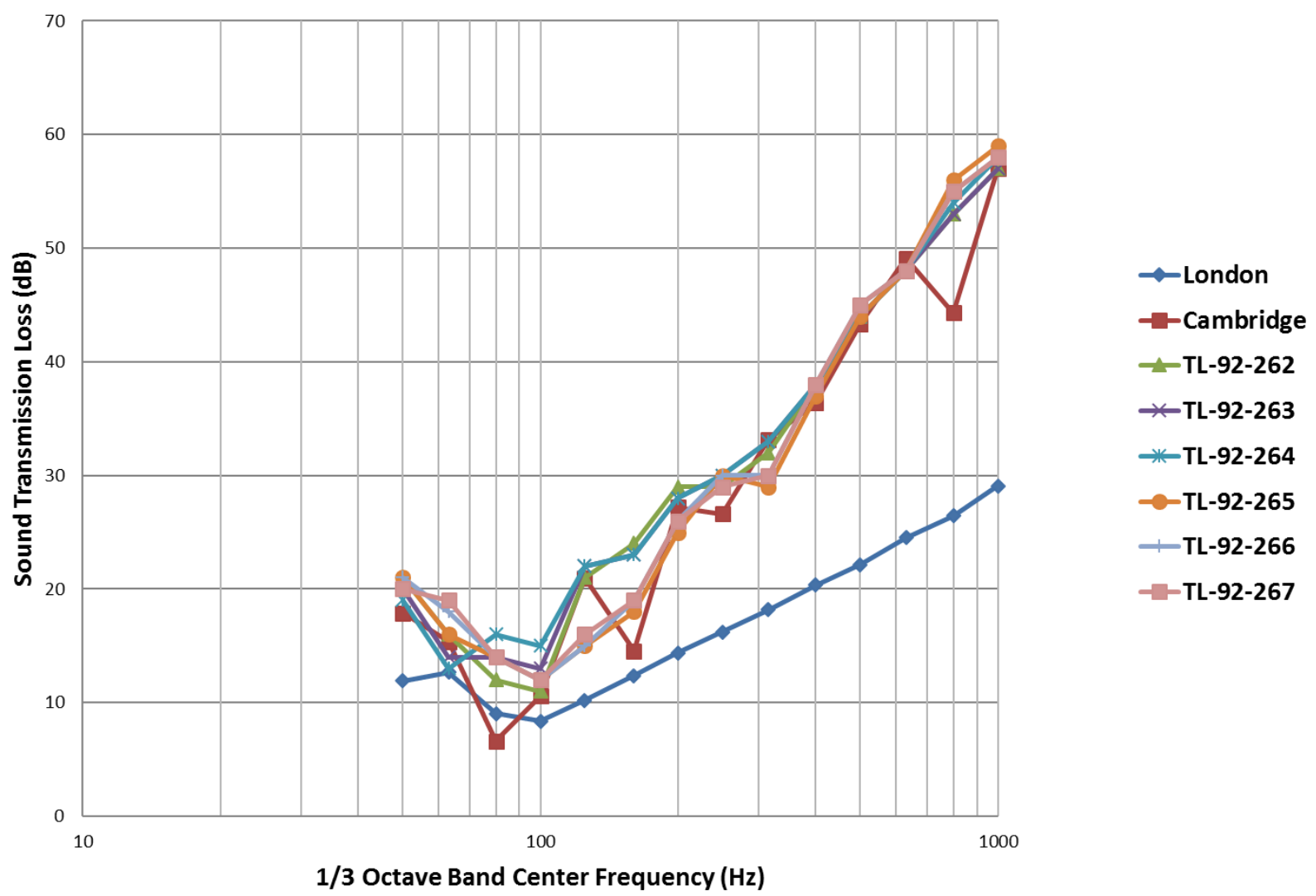
waves within the wall cavity due to its finite size, more realistic predictions are obtained.

398 Therefore, the physical explanation for the reason why London's model under-predicts the STL

399 comes from the effect of the angular dependent mass-air-mass resonance frequency.

The link between the angular dependent mass-air-mass resonance frequency and 401 London's under-prediction of the STL has not been reported within the literature. Although 
402 Prasetiyo and Thompson's (2012) recent publication which is based on the coupled Waveguide 403 Finite Element-Wavedomain Boundary Element method to predict the STL showed that the 404 oblique resonance does not vary with the angle of incidence (an observation which agrees with 405 the results presented here); they could not use their results to explain the reason why London's 406 model under-predicted the STL since they were not able to predict the normal mass-air-mass 407 resonance frequency with their model. Instead, their first resonance occurred at the point where 408 the first cavity resonance (i.e $n_{x}=1$ ) combined with the normal mass-air-mass resonance 409 frequency. Despite this fact, even though the technique presented here is different from Prasetiyo 410 and Thompson's (2012), the results obtained from both models indicate that the lateral cavity

411 modes do have a significant impact on the prediction results obtained for the STL through 412 double-leaf wall systems.

\section{VII. SOUND TRANSMISSION LOSS OF AN EMPTY DOUBLE-LEAF WALL}

414 In the previous section it was assumed that the same radiation efficiency could be used for the 415 vibrations created by both the forced and reflected forced waves. This assumption is not entirely 416 valid as the radiation efficiencies of both waves are different since their wavelengths and rates of 417 attenuation are not the same. The predicted STL when considering the radiation efficiency of the

418 reflected waves can be seen in Figure 7. The effect of considering the different radiation 419 efficiencies of the reflected waves can be seen by comparing the predicted STL shown in Figure $420 \quad 6$ and Figure 7. 


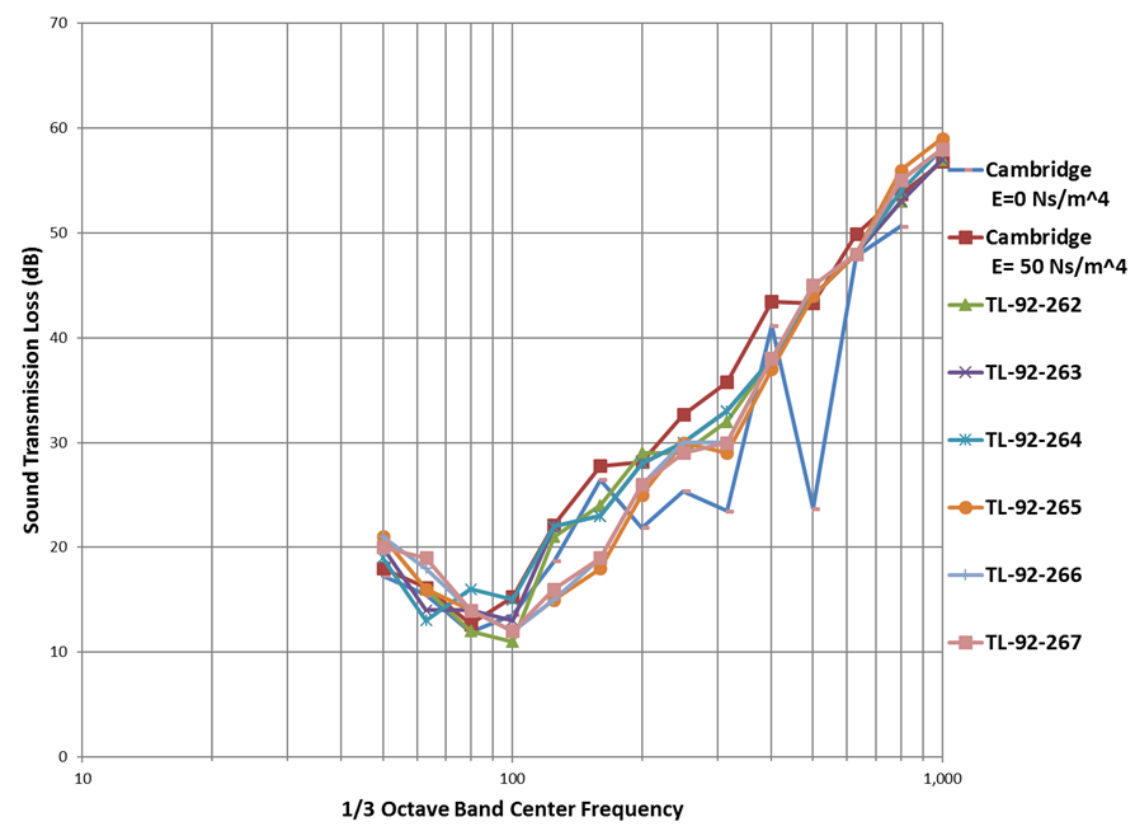

421

422

423

424

425

426

427

428

429

430

431

432

433

434

Figure 7 STL of a $16 \mathrm{~mm}$ gypsum double-leaf wall with a $90 \mathrm{~mm}$ cavity without sound absorption material (color online)

The results shown in Figure 7 show the predicted results with air flow resistivity of 0 and $50 \mathrm{Ns} / \mathrm{m}^{4}$. For the presented model an air-flow resistivity of $50 \mathrm{Ns} / \mathrm{m}^{4}$ is necessary because the empty cavity provides some absorption of sound in addition to that provide by the radiation of sound from the outer sides of each wall panel. This result is consistent with Gösele and Gösele's (1977) result that the radiation of sound from one wall is equivalent to an airflow resistivity of between 1 and $10 \mathrm{Ns} / \mathrm{m}^{4}$.

In order to obtain the results shown in Figure 7, a resistance term of $r=600 \mathrm{~kg} /\left(\mathrm{m}^{2} \mathrm{~s}\right)$ for the vibration of the wall leaves was included in the model to reduce the extent of the singularity obtained at the mass-air-mass resonance frequency $\left(f_{\mathrm{o}}\right)$. The effect of different values of this resistance term $r$ on the STL can be seen in Figure 8. This resistance term is needed physically because real wall panels will have some damping. 
waves, is expressed as the approximate percent relative error $\left(\varepsilon_{a}\right)$ which is given by

$$
\varepsilon_{a}=\frac{\text { present approximation }- \text { previous approximation }}{\text { present approximation }} 100 \% \text {, }
$$

437 Chapra and Canale (2002), for successive iterations around $f_{o}$ is given in Table 1. From the results shown in Table 1 it can be seen that with successive iterations the diffuse sound field STL 439 rapidly converges. Similar rates of convergence were obtained for the STL at discrete 440 frequencies for different angles of incidence as well as for the radiation efficiency of the 441 reflected waves. As a result of the small $\varepsilon_{a}$ which occurs by the 4th iteration, only four iterations 442 were used for all the prediction results presented in this paper.

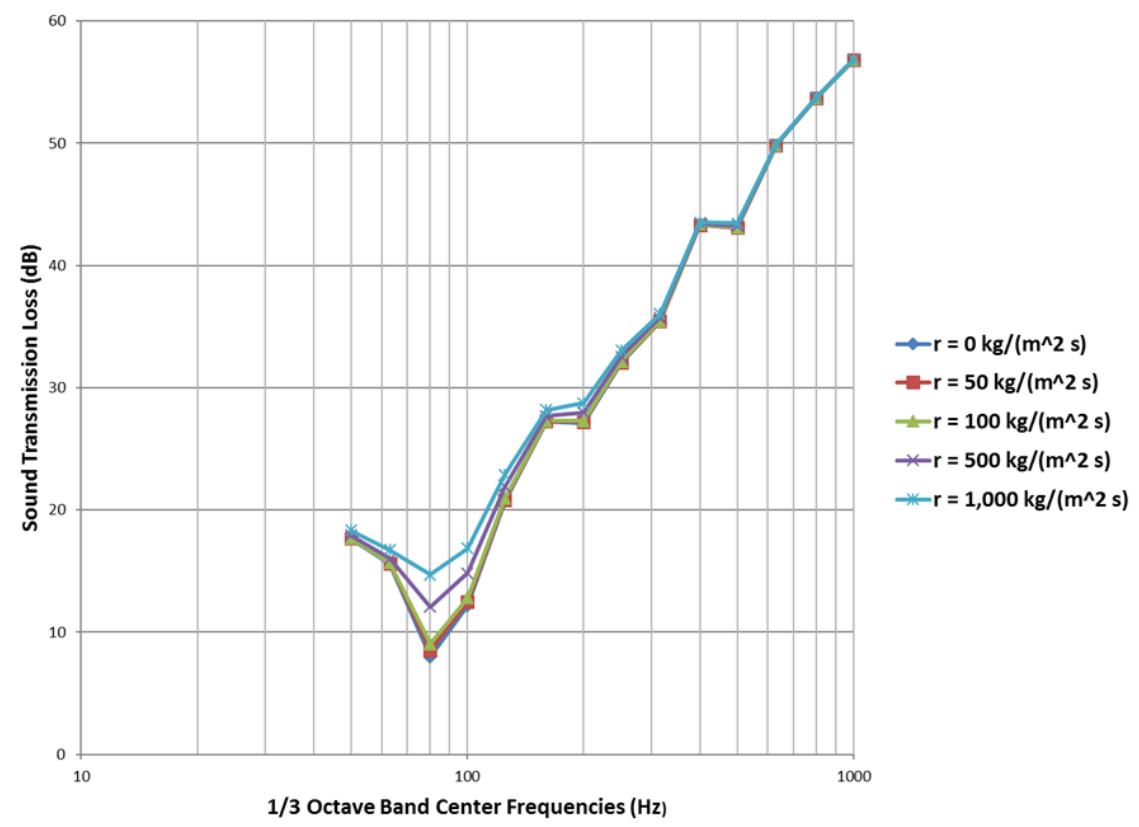

Figure 8 Effect of the resistance term $r\left(\mathrm{~kg} /\left(\mathrm{m}^{2} \mathrm{~s}\right)\right)$ on the predicted STL for a $16 \mathrm{~mm}$ double-leaf gypsum wall system without sound absorption material (i.e. airflow resistivity= $50 \mathrm{Ns} / \mathrm{m}^{4}$ ) (color online) 
Table 1 Approximate percent relative error of the STL for successive iterations of the radiation efficiency of the reflected waves

\begin{tabular}{|cccc|}
\hline $\mathbf{1 / 3}$ Octave Band Centre Frequency $\mathbf{H z})$ & Iteration $\mathbf{2}$ & Iteration $\mathbf{3}$ & Iteration 4 \\
\hline $\mathbf{8 0}$ & $2.62 \mathrm{E}-02$ & $-4.56 \mathrm{E}-04$ & $8.28 \mathrm{E}-06$ \\
\hline $\mathbf{1 0 0}$ & $-1.21 \mathrm{E}-02$ & $6.52 \mathrm{E}-05$ & $-3.49 \mathrm{E}-07$ \\
\hline $\mathbf{1 2 5}$ & $-2.02 \mathrm{E}-03$ & $2.69 \mathrm{E}-06$ & $1.80 \mathrm{E}-09$ \\
\hline $\mathbf{1 6 0}$ & $5.63 \mathrm{E}-04$ & $-1.03 \mathrm{E}-06$ & $1.91 \mathrm{E}-09$ \\
\hline $\mathbf{2 0 0}$ & $-1.21 \mathrm{E}-03$ & $1.57 \mathrm{E}-06$ & $-2.05 \mathrm{E}-09$ \\
\hline
\end{tabular}

The results in Figure 7 show that the derived model accurately predicts the STL for the

451 empty double-leaf wall system below and above $f_{0}$ up until approximately half of the critical

452 frequency of the wall panel once suitable resistivity (i.e. $\Xi$ ) and resistance (i.e. $r$ ) is included.

45BIII. SOUND TRANSMISSION LOSS OF A FULLY FILLED DOUBLE-LEAF WALL

Research conducted by Gösele and Gösele (1977), Novak (1992), Narang (1993; 1995) and Royar (2007) showed that an airflow resistivity of approximately $5000 \mathrm{Ns} / \mathrm{m}^{\wedge} 4$ is needed to damp the modes within the wall cavity. Above this airflow resistivity little improvement in the

457 STL is obtained. The developed model was used to verify this trend for a $16 \mathrm{~mm}$ double-leaf 458 wall gypsum board system with varying airflow resistivity within a $90 \mathrm{~mm}$ cavity as shown in 459 Figure 9. These results indicate that as the airflow resistivity is increased, the STL steadily 460 increases up until an airflow resistivity of approximately $5000 \mathrm{Ns} / \mathrm{m}^{\wedge} 4$. Above this airflow 461 resistivity little improvement in the STL occurs; a result which is supported by other work within 462 the literature. However, although the developed model followed the expected trend, in order to 463 determine the accuracy of the model, comparisons were made to experimental data. 


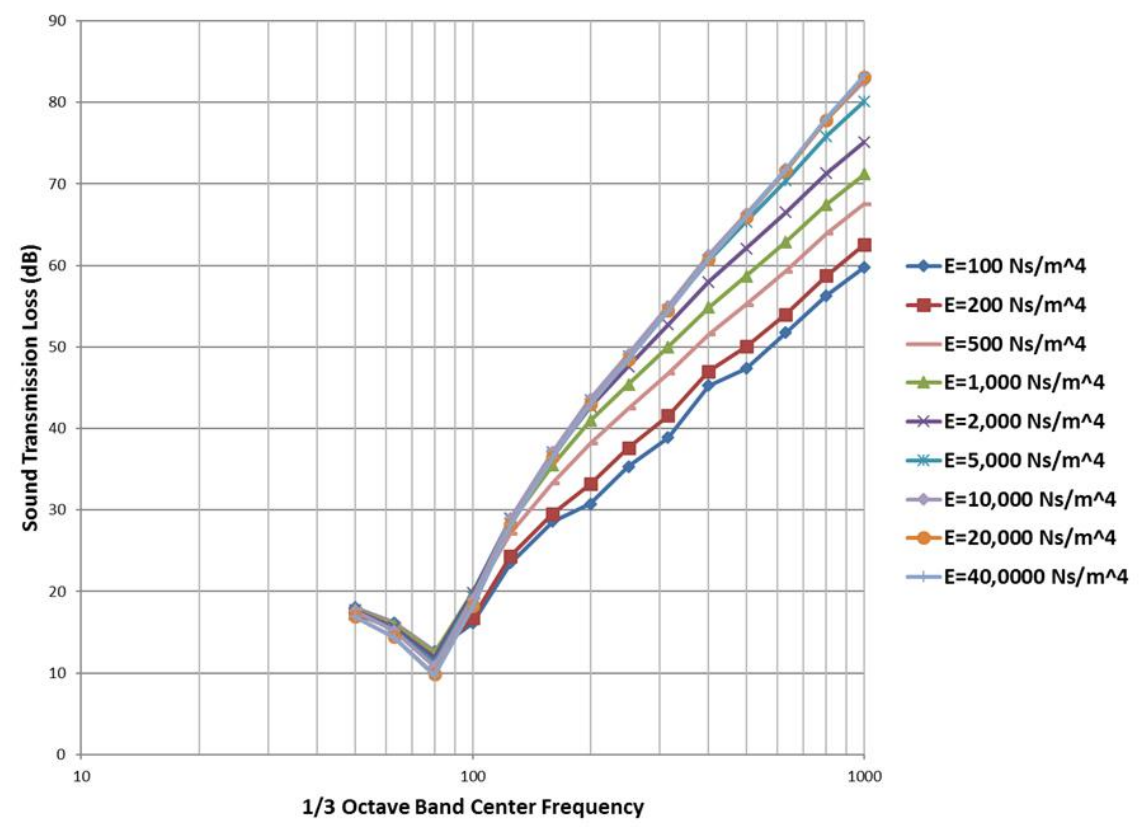

464

465

Figure 9 Effect of different airflow resistivity (color online)

The prediction for the STL of a $16 \mathrm{~mm}$ gypsum double-leaf wall system, with glass-fibre

467 (flow resistivity $4800 \mathrm{Ns} / \mathrm{m}^{4}$ ) within a $90 \mathrm{~mm}$ cavity, can be seen in Figure 10. TL-92-268 to

468 TL-92-274 contain $40 \mathrm{~mm}$ double steel studs spaced at $610 \mathrm{~mm}$ centers with a $10 \mathrm{~mm}$ gap

469 between the separate studs, while TL-92-275 does not contain any studs, Warnock (2010). These

470 walls have a critical frequency of $2.5 \mathrm{kHz}$. 


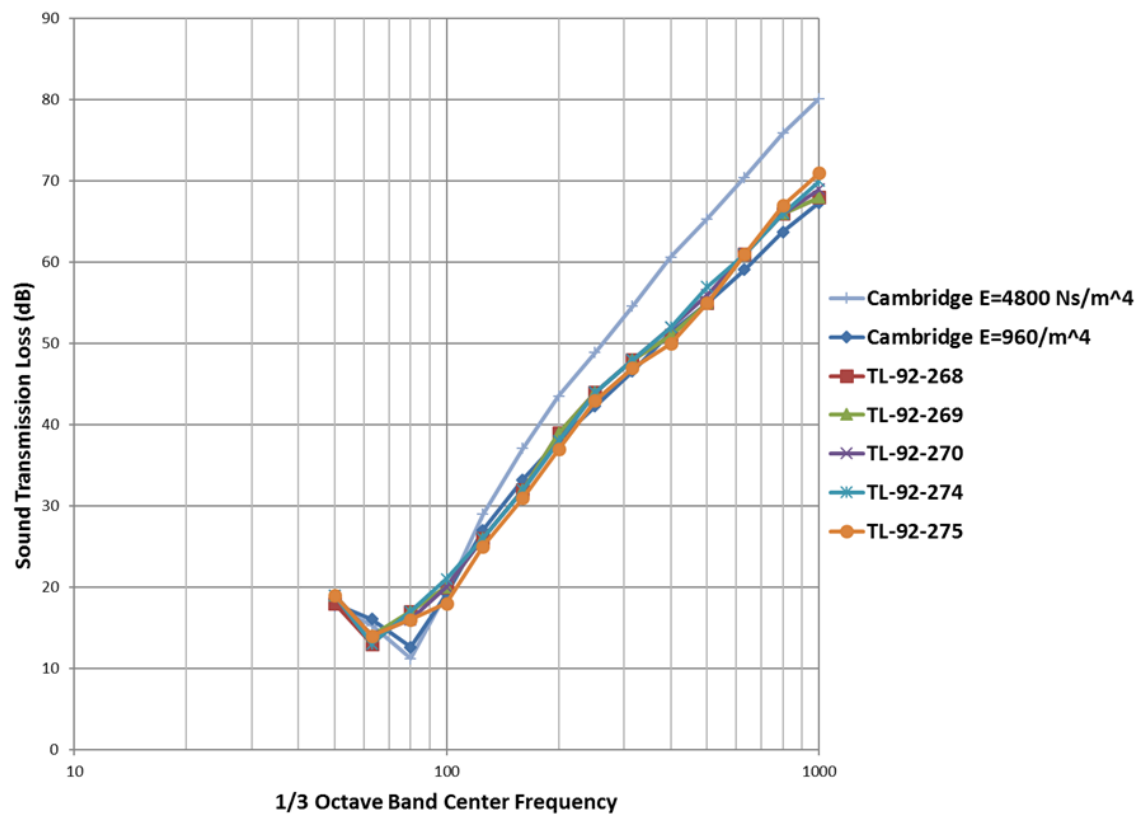

471

472 Figure 10 STL of a double-leaf wall system with glass-fibre within the $90 \mathrm{~mm}$ wall cavity (color online)

Figure 10 shows the predicted results with the measured glass-fibre air flow resistivity of $4754800 \mathrm{Ns} / \mathrm{m}^{4}$ as well as the results obtained when $20 \%$ of the measured airflow resistivity of the material was utilized. The reduction in the glass-fibre airflow resistivity was necessary because a

477 higher than expected STL was obtained when the actual airflow resistivity of $4800 \mathrm{Ns} / \mathrm{m}^{4}$ was 478 used in the developed model as shown in Figure 10. A similar problem was observed by Novak 479 (1992) within his transfer matrix model which utilized the airflow resistivity of the material in 480 the wall cavity in order to predict the sound insulation of a cavity wall. Novak did not give an 481 explanation for this result. However, with regard to the proposed model there are three plausible 482 reasons why the overestimate occurs when the actual flow resistivity is used.

1. The reported airflow resistivity is usually measured normal to the surface of the material and not in a planar direction. Allard and Atalla (2009) noted that fibrous materials are 
generally anisotropic and the fibres generally lie in planes parallel to the surface of the material. As a result, the normal airflow resistivity $\left(\Xi_{n}\right)$ which is measured perpendicular to the planes of the fibres is different from the planar airflow resistivity $\left(\Xi_{p}\right)$ which is measured parallel to the directions of the planes. Allard (1987) discussed the work of Burke (1983) and Nicholas and Berry (1984) which showed that the ratio of the planar to

normal airflow resistivity was approximately 0.5. Consequently, since the developed model was derived by integrating along the length of the cavity rather than across its depth, the planar airflow resistivity should be utilized within the model rather than the usual reported normal airflow resistivity. This issue relating to direction of the measured airflow resistivity gives a plausible explanation for the reason why at most $50 \%$ of the measured normal airflow resistivity should be used within the developed model. This issue has also been studied by Tran-Van (2004).

2. The assumption within the developed model that the sound absorbing material within the wall cavity does not move when excited by the sound waves. Schultz (Beranek, 1971) discussed the properties of porous materials when excited by sound waves. In this discussion Schultz noted that in the low frequency region if the material has insufficient inertia to remain motionless it will move as a whole because of the action of the air particles pumped back and forth by the sound pressure through the pores of the blanket. Schultz concluded that under such circumstances the blanket can be treated in terms of lumped constants with no consideration of sound propagation within the blanket (Beranek, 1971). No sound propagation within the blanket means that the sound absorption properties will be drastically reduced. Consequently, if there is any movement of the sound absorption material within the wall cavity for the frequency range 
considered, the airflow resistivity required for these calculations would be significantly lower. Although it can be argued that the movement of the sound absorption material may not significantly affect the predictions from the developed model since the movement of the material in the normal direction will be greater than the planar direction, it must be noted that any movement of the material in any direction will cause some reduction in its sound absorption properties and reduce the required airflow resistivity needed for the model. The extent of this required reduction in airflow resistivity if the sound absorption material moves within the wall cavity is unknown. It may be possible in the future to incorporate the inertia of the sound absorbing material into the model described in this paper using the limp frame equivalent fluid model found in Allard and Atalla (2009).

3. The sound radiation into the wall cavity. The developed model is based on the assumption that below the critical frequency the forced bending waves are efficient radiators while the free bending waves are inefficient. The hydrodynamic short circuiting of the free bending waves within the finite wall panel is responsible for the inefficiency of these waves. However, although this may be true for radiation into a free space or into an empty wall cavity, Tomlinson et al. (2004) showed that the radiation efficiency of the free bending waves on a plate increases as the airflow resistivity of the porous medium it is radiating into increases. For example, Tomlinson et al. calculated the radiation efficiency of a plate at $100 \mathrm{~Hz}$ radiating into a $100 \mathrm{Ns} / \mathrm{m}^{\wedge} 4$ porous medium as 0.018 and approximately 0.3 into a $5000 \mathrm{Ns} / \mathrm{m}^{\wedge} 4$ medium. Clearly the significance of the free bending waves increases as the airflow resistivity increases below the critical frequency. Because the wall leaves are assumed to be limp in this paper, there cannot be reflected 
542 due to the change in the speed of sound through the porous material as discussed by Narang 543 (1993). For wall systems with a $205 \mathrm{~mm}$ deep cavity using $40 \%$ of the reported airflow 544 resistivity when more than $50 \%$ of the cavity is filled produces satisfactory results Cambridge 545 (2012).

\section{IX. SUMMARY AND CONCLUSIONS}

547 A model to determine the STL through both the infinite and the finite double-leaf wall 548 systems by studying the propagation of the forced and reflected waves in the wall cavity has 549 been developed. The infinite model's prediction compared well with London's model, while the 550 deteriorating effect of the angular dependent mass air mass resonance frequency was given as the 551 main reason why London's model under-predicts the STL. The predictions obtained when the 552 difference between the radiation efficiency of the forced and reflected waves was taken into 553 account also compared well to experimental data for both the empty and full cavity case although 
554 an additional resistance term and a reduced airflow resistivity had to be incorporated within the 555 model. The inclusion of the additional resistance term $r$ was needed to reduce the extent of the 556 reduction in the prediction of the STL at the mass air mass resonance frequency. The reduction 557 in the required airflow resistivity was needed because:

558 - The planar airflow resistivity is approximately $50 \%$ of the usually normal airflow $559 \quad$ resistivity

560 - There is a possibility that the sound absorption material may move within the cavity, 561 therefore reducing its sound absorption properties

- The radiation of sound by the free bending waves in the wall leaves was not included in The issues encountered while using the airflow resistivity of the material to model its sound 568 absorption characteristics is consistent with that encountered by Novak (1992), although no 569 explanation was given by him for the reason why an over prediction of the STL occurred once 570 the actual normal airflow resistivity was used.

571 


\section{REFERENCES}

573 Allard, J. F. (1987). "Anisotropy effect in glass wool on normal impedance in oblique

574 incidence," J. Sound Vib. 114, 233-238.

575 Allard, J. F., and Atalla, N. (2009). Propagation of Sound in Porous Media: Modelling Sound

576 Absorbing Materials (John Wiley and Son Chichester), pp. 358.

577 Beranek, L. (ed). (1971). Noise and vibration control (McGraw-Hill Inc, New York ), pp. 650.

578 Beranek, L. L., and Work, G. A. (1949). "Sound insulation through multiple structures

579 containing flexible blankets," J. Acoust. Am. Soc. 21, 419-428.

580 Brunskog, J. (2012). "The forced sound transmission of finite single leaf walls using a variational 581 technique," J Acoust Soc Am 132, 1482-1493.

582

583

584
Brutel-Vuilmet, C. (2005). "Consideration of the angle of incidence in the characteristisation in the laboratory of facade elements," (L'Institut National des Sciences Appliquées de Lyon, Lyon), p. 193.

Brutel-Vuilmet, C., Guigou-Carter, C., Villot, M., and Jean, P. (2006). "Measurement of the Sound Reduction Index as a Function of the Incidence Angle by two Different Methods," Build. Acoust. 13, 33 - 48.

Burke, S. (1983). "The absorption of sound by anisotropic porous layers " in 106th Meeting of the ASA November 1983 (San Diego, California), S58.

Cambridge, J. E. (2012). "The Sound Insulation of Cavity Walls " in Mechanical Engineering (University of Canterbury Christchurch, New Zealand), pp. 198.

Chapra, S. C., and Canale, R. P. (2002). Numerical methods for engineers with software and programming applications (Mc Graw Hill, Boston), pp. 968.

Davy, J. L. (2009a). "The forced radiation efficiency of finite size flat panels that are excited by incident sound " J. Acoust. Am. Soc. 126, 694-702.

Davy, J. L. (2009b). "Predicting the sound insulation of walls " Building Acoustics 16, 1-20. 
Davy, J. L. (2010). "The improvement of a simple theoretical model for the prediction of the sound insulation of double leaf walls," J. Acoust. Soc. Am. 127, 841-849.

Fahy, F. (1985). Sound and structural vibration: Radiation, transmission and response (Academic Press, London), pp. 309.

Ghinet, S., and Atalla, N. (2001). "Sound Transmission Loss of Insulating Complex Structures " in Canadian Acoustics Vol 29 No. 3, pp. 26-27.

Gösele, V. K., and Gösele, U. (1977). "Einfluß der Hohlraumdämpfung auf die Steifigkeit von Luftschichten bei Doppelwänden (Influence of cavity volume damping on the stiffness of air layers in double walls)," Acustica 38, 159-166.

Heckl, M. (1964). "Einige Anwendungen des Reziprositätsprinzips in der Akustik (Some applications of the reciprocity principle in acoustics)," Frequenz 18, 299-304.

Hongisto, V. (2006). "Sound insulation of double panels - comparison of existing prediction models," Acta Acustica United With Acustica 92, 61-78.

Jacobsen, F., and Juhl, P. (2011). "Radiation of Sound " (http://webfiles.ait.dtu.dk/fjac/p_home_page/notes/Radiation.pdf Technical University of Denmark and University of South Denmark ), pp. 17-23.

Ljunggren, S. (1991). "Airborne sound insulation of thin walls " J. Acoust. Am. Soc. 89, 23242337.

London, A. (1950). "The determination of reverberant sound absorption coefficients from acoustic impedance measurements," J. Acoust. Soc. Am. 22, 263-269.

Narang, P. P. (1993). "Effect of fiberglass density and flow resistance on sound transmission loss of cavity plasterboard walls," Noise Control Engineering Journal 40, 215-220.

Narang, P. P. (1995). "Material parameter selection in polyester fibre insulation for sound transmission and absorption " Applied Acoustics 45, 335-358.

Nicolas, J., and Berry, L. J. (1984). "Propagation du son et effet de sol (Sound propagation and ground effect)," Revnue d'Acoustique, 191-200. 
Novak, R. A. (1992). "Sound insulation of lightweight double walls " Applied Acoustics 37, 281-303.

Prasetiyo, I. (2012). "Investigation of sound transmission in lightweight structures using a waveguide finite element/boundary element approach," in Faculty of Engineering and the Environment, Institute of Sound and Vibration Research (University of Southampton, Southampton), pp. 268.

Prasetiyo, I., and Thompson, D. J. (2012). "Effect of finite air cavity and steel studs on sound transmission loss of lightweight double panel systems," in Euronoise (European Acoustics Association, Prague), pp. 156-161.

Rindel, J. H. (1975). "Transmission of traffic noise through windows, influence of incident angle on sound insulation in theory and experiment " (Technical University of Denmark, Lyngby), pp 10 .

Royar, J. (2007). "Different influence of mineral wool airflow resistivity on performance of sound transmission loss constructions," in Inter-noise 2007 (Istanbul, Turkey ), pp 10.

Sato, H. (1973). "On the mechanism of outdoor noise transmission through walls and windowsA modification of infinite wall theory with respect to radiation of transmitted wave " The Acoustical Society of Japan 29, 509-516.

Sewell, E. C. (1970). "Transmission of reverberant sound through a single-leaf partition surrounded by an infinite rigid baffle " J. Sound Vib. 12, 21-32.

Tomlinson, D., Craik, R. J. M., and Wilson, R. (2004). "Acoustic radiation from a plate into a porous medium " J. Sound Vib. 273, 33-49.

Tran-Van, J. (2004). "Etude de l'influence de l'isotropie transverse des laines minérales sur la transmission acoustique des parois multicouches (Study of the influence of the transverse isotropic mineral wool on the acoustic transmission multilayer walls)," (Universite de Poitiers.), pp. 201.

Vigran, T. E. (2009). "Predicting the sound reduction index of finite size specimen by a simplified spatial windowing technique," J. Sound Vib. 325, 507-512.

Villot, M., and Guigou-Carter, C. (2005). "Using spatial windowing to take the finite size of plane structures into account in sound transmission," in NOVEM (St. Raphael, France), pp. 1-8. 
652 Villot, M., Guigou, C., and Gagliardini (2001). "Predicting the acoustical radiation of finite size 653 multi-layered structures by applying the spatial windowing on infinite structures " J. Sound Vib. $654245,433-455$.

655 Warnock, A. C. C. (2010). "Sound transmission loss measurements: Personal communication via 656 A. Warnock and J. Davy," (National Research Council of Canada ), pp. 1.

657

658 